\title{
Effect of Light on the Sensitivity of CuS Thin Film EGFET Implemented as pH Sensor
}

\author{
Fayroz A. Sabah ${ }^{1,2, *}$, Naser M. Ahmed ${ }^{1, *}$, Z. Hassan $^{1}$, Munirah Abdullah Almessiere ${ }^{3}$ \\ ${ }^{1}$ Institute of Nano-Optoelectronics Research and Technology (INOR), School of Physics, Universiti \\ Sains Malaysia, 11800 Penang, Malaysia \\ ${ }^{2}$ Department of Electrical Engineering, College of Engineering, Al-Mustansiriya University, Baghdad, \\ IRAQ \\ ${ }^{3}$ Physics Department, College of Science, University of Dammam, Saudi Arabia \\ *E-mail: fayroz_arif@yahoo.com, naser@usm.my
}

doi: $10.20964 / 2016.06 .51$

Received: 29 February 2016 / Accepted: 8 April 2016 / Published: 4 May 2016

\begin{abstract}
The lightness and darkness affect the sensitivity of thin films considered as extended-gate field-effect transistor (EGFET) for $\mathrm{pH}$ sensor, for this reason the research work was investigated to study these effects for $\mathrm{CuS}$ thin film. CuS thin film prepared by copper chloride and sodium thiosulfate using deionized water as a solvent, deposited on a glass substrate by spray pyrolysis deposition. The structural properties were studied through X-ray diffractometer, and the morphological properties were studied through field emission scanning electron microscopy. Then this thin film was used as an extended gate of the field effect transistor to be implemented as $\mathrm{pH}$ sensor. The sensitivity was measured for this extended gate under two conditions; dark and light source. The results showed the highest sensitivity $(23 \mathrm{mV} / \mathrm{pH})$ and less hysteresis $(2.6 \mathrm{mV})$ and drift $(13.1,73.5$ and 85.8 for $\mathrm{pH} 4$, $\mathrm{pH} 7$ and pH10, respectively) of the sensor in dark. While under high-intensity white light the sensitivity was $(19 \mathrm{mV} / \mathrm{pH})$ and the hysteresis had the value $(5.2 \mathrm{mV})$ and drift values were $(21.7$, 155.8 and 90.4 for $\mathrm{pH} 4, \mathrm{pH} 7$ and $\mathrm{pH} 10$, respectively). This confirmed that the extended gate of the field effect transistor is sensitive to light, and the light decreased the $\mathrm{pH}$ sensitivity.
\end{abstract}

Keywords: $\mathrm{CuS}$ thin film; EGFET; light; sensitivity; pH sensor.

\section{FULL TEXT}

(C) 2016 The Authors. Published by ESG (www.electrochemsci.org). This article is an open access article distributed under the terms and conditions of the Creative Commons Attribution license (http://creativecommons.org/licenses/by/4.0/). 